\title{
A State of the Art Report on Ultra High Performance Concrete: Reactive Powder Concrete
}

\author{
Bhusari J. P. ${ }^{1}$, Gumaste K. S. ${ }^{2}$ \\ ${ }^{I}$ (Ph.D. Scholar, Department of Civil Engineering, Walchand College of Engineering, Sangli, India
}

\begin{abstract}
There has been continuous demand for materials with higher compressive strength for various civil engineering applications. Reactive powder concrete (RPC) has been developed to overcome the weakness of most high strength concrete available with compressive strength in the range of 60-100 MPa. RPC was developed from a special combination of constituent materials such as Portland cement, silica fume, quartz flour, fine silica sand, high-range water-reducer, water and steel fibers wherein attempts have been made to remove the coarse aggregate particles to make a very strong mortar with a very low water cement ratio. This paper presents a state of the art report reviewing the research in the area of the development of RPC, highlighting the enhanced performance in the mechanical properties of RPC in direct application of its use in structural members requiring high standards of strength coupled with superior performance and durability.
\end{abstract}

Keywords: -Reactive powder concrete, high strength, mechanical properties

\section{INTRODUCTION}

In the modern age for coping with a highly developed infrastructure a new material that demonstrates greatly improved strength and durability characteristics called Reactive Powder Concrete (RPC) has been developed. It is a homogeneous combination of cement, fine quartz, silica, silica fume and steel fibers (optional) with absentia of conventional coarse aggregate. Compressive strengths of 200 to $800 \mathrm{MPa}$, Young's modulus of 50 to $60 \mathrm{GPa}$, a tensile strength in between 6-13 MPa and fracture energies varied from 15,000 Jm-2 to 40,000 $\mathrm{Jm}-2$ been achieved with RPC, with special curing and setting conditions by P. Richard in 1995.[1]

RPC has very low water/cement ratio and largest particle size as fine quartz sand with a particle size between 150-600 $\mu \mathrm{m}$. This necessitates addition of polyacrylate based super plasticisers which allow the cement to be mixed with approximately the same ease as conventional concrete. The steel fibres used are generally 13 $\mathrm{mm}$ long with $0.15 \mathrm{~mm}$ diameter. Silica fume (SF) procured from the zirconia industry with Blaine fineness (14 $\mathrm{m} 2 / \mathrm{g})$ gives better result than the one with a high Blaine fineness value $(22 \mathrm{~m} 2 / \mathrm{g})$. Richard and Cheyrezy [1] initially tested the mix design which is considered as basic composition, obtaining a compressive strength of 170 $\mathrm{MPa}$ when cured for 28 days at ambient temperature and $230 \mathrm{MPa}$ when cured at $90{ }^{\circ} \mathrm{C}$ for $6-12$ hours after precuring at ambient temperature for 2 days. Addition of steel aggregates lead to achievement of compressive strength up to $800 \mathrm{MPa}$ with curing at $250^{\circ} \mathrm{C}$ and a preset pressure applied while in the mould.

\section{HIGH PERFORMANCE PARAMETERS}

Parameters relating to composition (homogeneity and granular compacted density) are the basis of the RPC concept and parameters relating to production (application of pressure and heat-curing) are optional parameters designed to enhance performance. In particular, following are the view points for the high performance of RPC.

\subsection{Improvement of Homogeneity}

Elimination of coarse aggregates, replaced by fine sand, improved mechanical properties of the paste, reduction in the aggregate / matrix ratio gives RPC homogeneous nature to enhance its physical properties eliminating modulus variance between the quartz and the surrounding paste [1]. This allows for mechanical properties to be transferred through the two mediums and ease out the effects associated with disturbance of the mechanical stress field.

\subsection{Optimisation of the granular mixture}

Optimisation of the granular mixture is achieved through packing models adopting 'Densified small particle' (DSP) compact granular matrix concretes developed by F. De Larrad [2]. P.Richard has suggested the particle size range from $150 \mu \mathrm{m}$ to $600 \mu \mathrm{m}$ in order to prevent interference with the largest cement particles (80$100 \mu \mathrm{m})$. Relative density characterizes the quality of the granular mixture, mixing and vibration efficiency in 
global terms with optimum water content [1]. Henry H.C. Wong presented a three-tier system design wherein packing density concept is adopted by adjusting the grading of the whole range of solid particles [3].

Olivier Bonneaua worked on the characterization of the granular packing and percolation threshold of RPC using electrical conductivity and isothermal calorimetry. A linear relationship between the logarithm of conductivity $\ln (\sigma)$ and the degree of hydration $\alpha$, has been found: $\ln (\sigma)=A_{v^{-}} B_{v} x \alpha$, where $A_{v}$ depends on the nature and the dosage of the different mineral and organic components, and $B_{v}$ is an invariant related to the granular packing [4]. Guangcheng Longastudied the compactness and fluidity of binary and ternary compound paste systems containing ultrafine powders such as pulverized fly ash, pulverized granulated blast furnace slag and silica fume with reference to relative density index and it was found that silica fume is most effective in improving the relative densities of binary paste systems [5].

\subsection{Microstructure enhancement by heat-curing and preset pressure}

P. Richard reported that heat-treating at $90^{\circ} \mathrm{Cat}$ ambient pressure substantially accelerates the pozzolanic reaction there by modifying the microstructure of the formed hydrates (amorphous) whereas high temperature heat-treating (at between $250^{\circ} \mathrm{C}$ and $400^{\circ} \mathrm{C}$ ), only applicable to fibered RPC, leads to the formation of crystalline hydrates (xonotlite) [1]. Marcel Cheyrezyalso adopted granulometry, heat treatment and setting pressure (1 atm, $310 \mathrm{~atm}, 625 \mathrm{~atm})$ to RPC. Porosimetric studies demonstrated the very low porosity of RPC (9 $\%$ in volume in the pore diameter range of $3.75 \mathrm{~nm}$ to $100 \mathrm{~nm}$ ) and nil for pressed RPC [6]. Confining pressure during the setting phase eliminated part of the porosity due chemical shrinkage and lead to relative density gains exceeding $6 \%$ thereby increasing compressive strength [1].

Metin studied various mixing ratio rates, fiber content and pre-setting pressure of $\operatorname{RPC}(0,5,10,15,20$, $25 \mathrm{MPa}$ ). Application of pre-setting pressure nearly doubled compressive strength of the samples [7].Dugat applied $60 \mathrm{MPa}$ pre-setting pressure to RPC 800 along with heat treatment cure $\left(90^{\circ} \mathrm{C}\right.$ and $\left.250^{\circ} \mathrm{C}\right)$. Consequently, they reached compressive strength of about $500 \mathrm{MPa}$ and Young's modulus of $36-74 \mathrm{GPa}$ [8].

\section{STUDIES ON PERFORMANCE OF RPC}

Various studies were carried out for evaluating the performance parameters of RPC. These studies are classified based on composition and curing methods adopted. Also size effect of specimens which affects the test results is mention worthy.

\subsection{Influence of materials}

S. Collepardi studied a modified RPC compared with original RPC basic composition mix, where a graded natural aggregate (max size $-8 \mathrm{~mm}$ ) was used to replace the fine sand and/or part of the cementitious binder. Contrast observations were made that if the quality of the cement matrix, in terms of its w/c ratio, is not changed, the addition of the graded aggregate does not reduce the compressive strength. When considered for a given workability level, then replacement of the entire fine sand and part of the cementitious binder (cement and silica fume) with the graded aggregate demanded higher w/c ratio, leading to decrease in the compressive strength [9]. Marios N. Soutsos adopted ternary blends (pulverised fly ash, GGBFS in combination with silica fume). Enhanced tensile strength and ductility with flexural strengths between 30 and $60 \mathrm{MPa}$ and fracture energies above $10000 \mathrm{Jm}-2$ have been reported [10]. Yin-Wen Chan et.al found that the steel fiber- matrix interfacial properties have been altered by the incorporation of silica fume in both the debonding and pullout processes. The incorporation of silica fume in RPC matrix may result in an early debonding than the case without silica fume (0\%). After debonding, the steel fibers undergo pullout process. The interfacial resistance during pullout has been toughened in different extent for the matrix with various silica fume contents. It is also observed that the toughening effect is related to the silica fume content. The toughening effect at pullout process is the most significant in the cases with $20 \%$ and $30 \%$ of silica fume content. However, when the silica fume content keeps increasing (the case of 40\%) the interfacial-toughening effect decreases. For the interfacialtoughening effect, the optimum silica fume content can be between $20 \%$ and $30 \%$ [11].

The steel fibers in the mix ( $1.5-3 \%$ by volume) enhance ductility. There an increase of flexural strength from $28 \mathrm{MPa}$ to $100 \mathrm{MPa}$ and fracture energies from $50 \mathrm{Jm}-2$ to 40,000 Jm-2 depending on amount of fibres added along with type of curing [1].

\subsection{Influence of curing conditions}

Masami Uzawa et.al developed a new cementitious composite material using reactive powder by simple curing process instead of adopting pressure techniques and desired strength within a range from 50 $\mathrm{N} / \mathrm{mm} 2$ to $230 \mathrm{~N} / \mathrm{mm}^{2}$ by changing the steam-curing time and temperature could be obtained [12]. Ming-Gin Lee evaluated samples with basic composition for compressive strength, bond strength (slant shear test), steel pull out strength, relative dynamic modulus, NDT tests; before and after accelerated aging [13]. Zhang Yunsheng prepared green RPC (C200 GRPC) with compressive strength of $200 \mathrm{MPa}$. The mechanical 
properties of the $\mathrm{C} 200$ GRPC made materials consisting of $40 \%$ Portland cement, $25 \%$ ultra fine slag, $25 \%$ ultra fine fly ash and $10 \%$ silica fume, $4 \%$ steel fibers (RPC volume fraction) are higher than the others. The corresponding compressive strength, flexural strength, fracture energy and fiber-matrix interfacial bonding strength are more than $200 \mathrm{MPa}, 60 \mathrm{MPa}, 30,000 \mathrm{Jm}-2$ and $14 \mathrm{MPa}$, respectively [14]. A. Cwirzen studied the basic mechanical properties; frost durability and bond strength (with normal hardened concrete) of the ultra high strength (UHS) mortars and concretes. The compressive strength varied between 170 and $202 \mathrm{MPa}$ for the heattreated specimens and between 130 and $150 \mathrm{MPa}$ for the same non-heat-treated specimens [15]. A. Zenati incorporated local mineral additions; dunes sand and slag. The amorphous structure makes the ground slag reactive at early ages ( $\mathrm{T}<14$ days), but its low silica content influences its long-term ( $\mathrm{T}>14$ days) pozzolanic reactivity. The ground dunes sand, although its crystalline state, becomes reactive at long-term, when it is added with $10 \%$ of amorphous addition. The results also show that the rheological behavior is influenced by the proportion of superplasticizer. Optimized constant proportion of plasticizer is about $1.8 \%$ though the flow times remain very high at this proportion [16]. Mechanical properties of RPC produced with class-C fly ash (FA) and GGBFS were investigated under different curing conditions (standard, autoclave and steam curing) by HalitYazici. Test results indicate that, compressive strength of RPC increased considerably after steam and autoclaving compared to the standard curing. On the other hand, it was observed that steam and autoclave curing decreased the flexural strength and toughness. Increasing the GGBFS and/or FA content improved the toughness of RPC [17]. T.P. Chang conducted tests on RPC specimens with two different curing conditions, water-curing of $25^{\circ} \mathrm{C}$ and steam-curing of $85^{\circ} \mathrm{C}$ and $95 \%$ relative humidity [18]. HalitYaziciinvestigated the mechanical properties by replacing cement with high volumes of GGBFS at $20 \%, 40 \%$ and $60 \%$. Sintered bauxite, granite and quartz were used in different series. The compressive strength of RPC with high volume GGBFS was over $250 \mathrm{MPa}$ after autoclaving and $400 \mathrm{MPa}$ when an external pressure of $30 \mathrm{MPa}$ was applied [19].

\subsection{Size effect}

The coefficient and law of the size effect of RPC were studied by AN Ming-zhe. They indicate that RPC without fiber behaves quite the same as normal or high strength concrete. The ratio of compressive strength of a $100 \mathrm{~mm}$ specimen to that of a $70.7 \mathrm{~mm}$ specimen is 0.98 . The size effect on compressive strength is more prominent in RPC containing fiber [20].

\section{COMPRESSIVE STRESS - STRAIN RELATIONSHIP}

WenzhongZheng carried an experimental research on RPC with various steel fiber contents after exposure to $20^{\circ} \mathrm{C}-900^{\circ} \mathrm{C}$. The results indicate that the compressive strength and elastic modulus of RPC increase at first, then decrease with the increasing temperature, and the loss of elastic modulus is quicker than the loss in compressive strength [21]. Y.S. Tai as well asYonghua Wangconducted an experimental investigation on the dynamic mechanical properties of the RPC using Split Hopkinson pressure bar (SHPB) testing; for different fractions of fiber and different strain rate. The results show the obvious rate-dependent mechanical behaviour exists for RPC [22, 23]. Tai compared his results with that of Grote [24] who conducted a mortar experiment. For RPC, the presence of the steel fibres should increase the dynamic increase factor at highstrain rates. However trend is opposite. This is because of the excessively large difference between the static compression strength of the normal strength concrete and RPC. Regression analysis of all the test results gives a dynamic increase factor of RPC as $R=0.9198 \times e^{0.00062 \dot{\epsilon}}$.

Yonghua Wang considered two types of pulse shapers with different thicknesses to reduce the highfrequency-oscillation effect and achieve a nearly constant strain rate. He differentiated contribution of effects of the hydrostatic stress and strain rate for calculating the apparent dynamic strength enhancement [23]. Zhang Yunsheng carried dynamic testing to investigate the dynamic tensile behaviour of the C200 GRPC through the SHPB. His results demonstrate that with an increase of strain rate, the peak stress rapidly increases in the dynamic tensile stress-time curves. The incorporation of steel fibers greatly reduces the damage degree of GRPC under high speed impact [14]. A. Cwirzen reported the values of the modulus of elasticity for six main types of mixes with the highest value of $52 \mathrm{GPa}$ measured in the UHS concrete containing diabase aggregates and the lowest value of $40 \mathrm{GPa}$ for UHS mortars [15].

\section{SHRINKAGE}

This time-dependent behaviour of UHPC was observed by using long-term measurements in a climatic room $\left(20 \pm 2{ }^{\circ} \mathrm{C} ; 65 \pm 5 \% \mathrm{RH}\right)$ by $\mathrm{N}$. Cauberg [25]. The shrinkage of the samples is measured vertically $(300 \mu \mathrm{m})$ after a 2-day curing. A. Cwirzen reported the shrinkage values two times higher for the UHS mortars (RPC) in comparison with the UHS concretes. The lowest creep values were measured for the non-heat-treated UHS concretes than for UHS mortar [15].C.M. Tam measured drying shrinkage strains up to 130 days Low drying shrinkage due to the high packing density of RPC and partly due to the prestressing effect of silica fume which slows down the water evaporation and restrains the shrinkage; was reported [26]. 


\section{PERMEABILITY}

C.M. Tam measured water permeability coefficients. Low water permeability, with the permeability coefficient lower than that of the normal concrete by an order of magnitude was noted for RPC. Water permeability of RPC decreases as the water-to-binder ratio decreases. This may be attributed to the small pores found with low water-to-binder ratio and gross volume of CSH gel and crystals formed which block and disconnect the capillary pores [26].

\section{BLAST RESISTANCE}

Na-Hyun Yi carried comparative studies on NSC (30 MPa), UHSC (210 MPa) and RPC (200 MPa). The blast-resistant capacities were verified by blast tests using a $15.88 \mathrm{~kg}$ charge with a $1.5 \mathrm{~m}$ standoff distance, applying a blast load with strain rate of $278-457 / \mathrm{sec}$. Test results showed UHSC and RPC panel specimens having higher blast-resistant capacities than NSC specimens. Marios N. Soutsos (2003) conducted simple impact load tests without instrumentation on unreinforced slab of RPC. The concrete at the top powdered under repeated impacts but there was no tensile cracking. A cone of concrete sheared off from the underside of the slab after about 70 impacts when the slab thickness had been reduced due to the powdering on the top surface [27].

\section{ANALYTICAL MODELS}

Kazunorideveloped non-linear analytical model based on a fiber model technique for RPC beam subjected to rapid flexural loads. Load deflection relationship was developed from the moment curvature (M- $\theta$ ) relationship. For this, it was assumed that the constituent material RPC and reinforcement exhibit strain rate effects on mechanical properties [28]. Shear capacity of RPC thin webbed prestressed beams without shear reinforcement using RPC (150-170 MPa) was assessed by Yen Lei Voo[29]. A design model based on crack sliding and plasticity theory was developed. KatrinHabel developed analytical model depicting the flexural behavior of composite concrete elements assuming linear strain distribution over the cross section as in conventional reinforced concrete [30].

\section{RPC AS A REPAIR MATERIAL}

Ming-Gin Leecarried 1000 cycles of freezing and thawing on non-shrinkage high strength mortar (HSM) and RPC. HSM showed a reduction in compressive strength, slant shear strength, steel pull out strength, and dynamic modulus by $17,21,24$, and $25 \%$, compared with the corresponding values $6,7,5$, and $10 \%$, respectively for RPC. For NSC, the average values of relative dynamic modulus of elasticity based on resonant frequencies after 300 and 600 freeze-thaw cycles were 75 and $55 \%$, compared with the corresponding values of 96 and $92 \%$, respectively for RPC [13]. Ming-Gin Lee has alsoreported that the effects of compressive and flexural strengthening with bonding RPC of $10 \mathrm{~mm}$ thickness are about $200 \%$ and $150 \%$ more than those of NSC. The abrasion coefficient of RPC is about 8 times higher [31].

T.P. Chang conducted tests cylindrical specimens retrofitted with 10 and $15 \mathrm{~mm}$ of wrapping RPC with two different curing conditions, water-curing of $25^{\circ} \mathrm{C}$ and steam-curing of $85^{\circ} \mathrm{C}$ and $95 \%$ relative humidity. Indices of durability of RPC have substantially increased [18]. N. Caubergapplied RPC as overlays by constructing a composite member with UHPC overlay and a repair mortar, with overlays of 15 and $30 \mathrm{~mm}$. After two months, none of the fiber reinforced overlays of $30 \mathrm{~mm}$ showed cracking or debonding. Enhanced flexural behaviour with steel micro fibers and E-glass textile RPC was also studied for its use, especially for non-load bearing elements such as cladding panels [25].

\section{CONCLUSIONS}

This paper presents a state of the art report reviewing the research work undertaken in the area of the development of RPC, highlighting the enhanced performance in the mechanical properties. Conclusions made after reviewing the research papers are

- Silica fume in RPC matrix remarkably enhances the steel fiber -matrix bond characteristics. Optimal SFcement ratio has been found to be in 20\%-30\%. The results of slant shear tests shows bond strength of RPC/RPC did not have significant decrease even after 1000 cycles of freeze-thawing indicating excellent bond characteristics and durability. The bond strength with NSC in fresh state needs to be explored.

- Steam curing at $90^{\circ} \mathrm{C}$ and especially high pressure steam curing at high temperature gave better performance of RPC but restricts the use of RPC in only precast construction. This necessitates the need to explore behavior of RPC for in-situ construction.

- RPC in general exhibit relatively low drying shrinkage and water permeability. Excessive dosage of super plasticizer can lead to chemical compatibility problems leading in increase of above parameters. Dosage of super-plasticizer therefore needs to be optimized for required performance criteria. 
- Though the use of well graded aggregates did not change compressive strength at the same w/c ratio but decrease in flexural strength and workability was noted.

- Though RPC as a material is costly, its use in building with partial inclusion in critical parts of building along with NSC can be thought of for enhancing the behavior of the structure.

\section{REFERENCES}

[1] P. Richard, Marcel Cheyrezy, Composition of Reactive Powder Concretes, Cement and Concrete Research, 25/7, 1995, 1501-1511.

[2] F. De Larrard,Optimization of Ultra- high- performance concrete by use of a packing model, Cement and Concrete Research, 24/6, 1994, 997-1008.

[3] Henry H.C. Wong and Albert K.H. Kwan, Packing Density: A Key Concept for Mix Design of High Performance Concrete, Proceedings of the Materials Science and Technology in Engineering Conference, HKIE Materials Division, Hong Kong, 2005, 1-15.

[4] Olivier Bonneau, Christian Vernet and Pierre-Claude Aitcin, Characterization of the granular packing and percolation threshold of reactive powder concrete, Cement and Concrete Research, 30,2000,1861-1867.

[5] Guangcheng Long and Xinyou Wang, Very-high-performance concrete with ultrafine powders, Cement and Concrete Research, 32, 2002, 601-605.

[6] Marcel Cheyrezy, Vincent Maret, Laurent Frouin, Microstructural Analysis of RPC (Reactive Powder Concrete), Cement and Concrete Research, 25/7, 1995, 1491-1500.

[7] MetinIpek, KemalettinYilmaz, Mansur Sumer and Mehmet Saribiyik, Effect of pre-setting pressure applied to mechanical behaviours of reactive powder concrete during setting phase, Construction and Building Materials, 25, 2011, 61-68.

[8] Dugat J, Roux N and Bernier G, Mechanical properties of reactive powder concretes, Materials and Structures, 29, 1996, 233-403.

[9] S. Collepardi L. Coppola, R. Troli and M. Collepardi, Mechanical Properties of Modified Reactive Powder Concrete, ACI Special Publications 173, 1997, 1-22.

[10] Marios N. Soutsos, Stephen G. Millard, and KonstantinosKaraiskos, Mix Design, Mechanical Properties, and Impact Resistance of Reactive Powder Concrete (RPC), Proceedings of International RILEM Workshop on High Performance Fiber Reinforced Cementitious Composites in Structural Applications, 2006, $549-560$.

[11] Yin-Wen Chan and Shu-Hsien Chu, Effect of silica fume on steel fiber bond characteristics in reactive powder concrete, Cement and Concrete Research, 34, 2004, 1167-1172.

[12] Masami Uzawa, YoshihideShimoyama and Shigeo Koshikawa, Fresh and Strength Properties of New Cementitious Composite Material Using Reactive Powder, Report of the Research Institute of Industrial Technology, Nihon University, No 75, 2005, 1-11.

[13] Ming-Gin Lee, Chui-Te Chiu, and Yung-Chih Wang, The Study of Bond Strength and Bond Durability of Reactive Powder Concrete, Journal of ASTM International, 2/7, 2005, 1-10.

[14] Zhang Yunsheng, Sun Wei, Liu Sifeng, Jiao Chujie, Lai Jianzhong, Preparation of C200 green reactive powder concrete and its static-dynamic behaviours, Cement \& Concrete Composites, 30, 2008, 831-838.

[15] A. Cwirzen, V. Penttala, C. Vornanen, Reactive powder based concretes: Mechanical properties, durability and hybrid use with OPC, Cement and Concrete Research, 38, 2008, 1217-1226.

[16] A. Zenati and K. Arroudj, Influence of cementitious additions on rheological and mechanical properties of reactive powder concretes, Proceedings of the JMSM 2008 Conference, Physics Procedia 2, 2009, $1255-126$

[17] HalitYazici and MertYucelYardimci, Mechanical properties of reactive powder concrete containing mineral admixtures under different curing regimes, Construction and Building Materials, 23, 2009, $1223-1231$.

[18] T.P. Chang, Performance of Reactive Powder Concrete (RPC) with different curing conditions and its retrofitting effects on concrete member, Concrete Repair, Rehabilitation and Retrofitting II, 2009, 12031208.

[19] HalitYazici, Mert Y. Yardım, HuseyinYigiter, Serdar Aydın and SelcukTurkel, Mechanical properties of reactive powder concrete containing high volumes of ground granulated blast furnace slag, Cement \& Concrete Composites, 32, 2010, 639-648.

[20] AN Ming-zhe, Z. Li-jun, YI Quan-xin, Size effect on compressive strength of reactive powder concrete, Journal of China University of Mining \& Technology, 18, 2008, 0279-0282.

[21] WenzhongZheng, Haiyan Li, Ying Wang, Compressive stress-strain relationship of steel fiber-reinforced reactive powder concrete after exposure to elevated temperatures, Construction and Building Materials, $35,2012,931-940$. 
[22] Y.S. Tai, The behaviour of reactive powder concrete at high strain rates, Magazine of Concrete Research, 62/11, 2010, 763-772.

[23] Yonghua Wang, Zhengdao Wang, Xiaoyan Liang and Minzhe An, Experimental and Numerical Studies on Dynamic Compressive Behavior of Reactive Powder Concretes, ActaMechanicaSolidaSinica, 21/5, 2008, 851-859.

[24] D. L. Grote, S.W. Park and M. Zhou, Dynamic behavior of concrete at high strain rates and pressure: I. Experimental characterization, International Journal of Impact Engineering, 25,2001, 869-886.

[25] N. Caubergand J. Piérard,Ultra High Performance Concrete: Mix design and practical applications, Tailor Made Concrete Structures - Walraven \&Stoelhorst, 2008, 1085-1087.

[26] C. M. Tam,Vivian W.Y. Tam, Assessing drying shrinkage and water permeability of reactive powder concrete produced in Hong Kong, Construction and Building Materials, 26, 2012, 79-89.

[27] Na-Hyun Yi, Jang-Ho Jay Kim, Tong-Seok Han, Yun-Gu Cho and Jang Hwa Lee, Blast-resistant characteristics of ultra-high strength concrete and reactive powder concrete, Construction and Building Materials, 28, 2012, 694-707.

[28] Kazunori Fujikake, TakanoriSenga, Nobuhito Ueda, Tomonori Ohno and Makoto Katagiri, Nonlinear Analysis for Reactive Powder Concrete Beams under Rapid Flexural Loadings, Journal of Advanced Concrete Technology, 4/1, 2006, 85-97.

[29] Yen Lei Voo, Stephen J. Foster and R. Ian Gilbert, Shear Strength of Fiber Reinforced Reactive Powder Concrete Prestressed Girders without Stirrups, Journal of Advanced Concrete Technology, 4/1, 2006, 123-132.

[30] KatrinHabel, Emmanuel Denarie and EugenBruhwiler, Structural Response of Elements Combining Ultrahigh-Performance Fiber-reinforced Concretes and Reinforced Concrete, Journal of Structural Engineering, 2006, 1793-1800.

[31] Ming-Gin Lee, Yung-Chih Wang, Chui-Te Chiu, A preliminary study of reactive powder concrete as a new repair material, Construction and Building Materials, 21, 2007, 182-189. 